This item was submitted to Loughborough's Research Repository by the author.

Items in Figshare are protected by copyright, with all rights reserved, unless otherwise indicated.

\title{
Exploring the wicked problem of athlete and consumer vulnerability in sport
}

PLEASE CITE THE PUBLISHED VERSION

https://doi.org/10.1108/JSOCM-07-2016-0035

PUBLISHER

() Emerald Publishing Limited

VERSION

AM (Accepted Manuscript)

PUBLISHER STATEMENT

This work is made available according to the conditions of the Creative Commons Attribution-NonCommercialNoDerivatives 4.0 International (CC BY-NC-ND 4.0) licence. Full details of this licence are available at: https://creativecommons.org/licenses/by-nc-nd/4.0/

\section{LICENCE}

CC BY-NC-ND 4.0

\section{REPOSITORY RECORD}

Westberg, Kate, Constantino Stavros, Aaron Smith, Joshua Newton, Sophie Lindsay, Sarah J. Kelly, Shenae Beus, and Daryl Adair. 2019. "Exploring the Wicked Problem of Athlete and Consumer Vulnerability in Sport". figshare. https://hdl.handle.net/2134/32506. 


\section{Exploring the wicked problem of athlete and consumer vulnerability in}

\section{sport}

\section{Abstract}

- Purpose: This paper extends the literature on wicked problems in consumer research by exploring athlete and consumer vulnerability in sport and the potential role that social marketing can play in addressing this problem.

- Design/methodology/approach: This paper conceptualises the wicked problem of athlete and consumer vulnerability in sport, proposing a multi-theoretical approach to social marketing, incorporating insights from stakeholder theory, systems theory and cocreation to tackle this complex problem.

- Findings: Sport provides a rich context for exploring a social marketing approach to a wicked problem as it operates in a complex ecosystem with multiple stakeholders with differing, and sometimes conflicting, objectives. It is proposed that consumers, particularly those that are highly identified fans, are key stakeholders that have both facilitated the problematic nature of the sport system and been rendered vulnerable as a result. Further, a form of consumer vulnerability also extends to athletes as the evolution of the sport system has led them to engage in harmful consumption behaviours. Social marketing, with its strategic and multi-faceted focus on facilitating social good, is an apt approach to tackle behavioural change at multiple levels within the sport system.

- Practical implications: Sport managers, public health practitioners and policymakers are given insight into the key drivers of a growing wicked problem as well as the potential for social marketing to mitigate harm.

- Originality/value: This paper is the first to identify and explicate a wicked problem in sport. More generally it extends insight into wicked problems in consumer research by 
examining a case whereby the consumer is both complicit in, and made vulnerable by, the creation of a wicked problem. This paper is the first to explore the use of social marketing in managing wicked problems in sport.

Key Words: Sport, Wicked Problems, Consumer vulnerability, Stakeholder Theory, Social Marketing

Paper Type: Conceptual 


\section{Introduction}

Sport provides many and varied benefits. Participation is associated with positive health outcomes and the development of aspirational qualities such as team work, leadership, perseverance and the pursuit of excellence (Eime et al., 2013; Holt et al., 2009).

Spectatorship and fandom offer entertainment, camaraderie and the shaping of identities (Stewart and Smith, 2000). Sport also has an alluring representative role, symbolically uniting communities and nations in support of athletes and teams and can even build bridges between countries and cultures (Tomlinson and Young, 2006). However, sport is increasingly plagued by a range of issues that reveal a dark side (Bloodworth and McNamee, 2010). These issues, as outlined in this paper, include allegations of athlete doping and match fixing and amplified consumer exposure to risky products such as alcohol and gambling (Stavros et al., 2016). Further, the increasingly commercial and pressurized environment of the sport system has contributed to problematic and anti-social behaviour by athletes not only within the sport arena but also outside of it (Fincoeur et al., 2013; Stewart and Smith, 2014). As well as being detrimental to the athletes concerned, this behaviour, which includes sexual assault, drug use, driving while intoxicated and illegal gambling, has wider implications for potentially normalising or desensitising undesirable behaviour in the community, which looks to sport for their heroes and role models (Parry, 2009; Rojek, 2006). Essentially this dark side runs counter to sport's positive social and cultural role in society, creating an environment that can render both athletes and fans vulnerable to behaviour that may compromise or threaten their well-being (Gucciardi et al., 2010).

The complexity of the sport system, including the varying interests and motivations of its multiple stakeholders, suggests that addressing this dark side of sport is emblematic of a wicked problem. A wicked problem is novel and unique, has no right or wrong answer, can 
be considered the symptom of another problem, carries no test for a solution or alternative, enumerable options and each solution is a discrete operation with no chance to build on trial and error (Conklin, 2006). Such a problem is one that is thus rarely, if ever solved. Its fluid, contradictory and amorphous nature is likely to impact significantly on society, but is often overlooked when solutions are sought given its complex and non-definitive formulation (Rittel and Webber, 1973). In the academic literature, wicked problems have been characterised as "ill-structured issues that have human relationships and interactions at their centre” (McGregor, 2012, p. 65) and involve complex social and political factors. These problems are difficult to define as they include multiple stakeholders with differing, and sometimes conflicting, perspectives on the issue as well as on the potential solutions (McGregor, 2012).

This conceptual paper seeks to contribute to the current understanding of wicked problems in consumer research by examining emerging social problems in the context of professional sport, from both consumer and athlete perspectives. The sport industry presents a rich case study for the impact of wicked problems given sport's deep social and cultural roots and its major commercial implications across both business and consumer sectors. We highlight the multi-aspects of the problem and the characteristics which suggest that the problem is indeed wicked. In unpacking these dynamic challenges and explicating the significant cultural and social role of sport, an interrelated and deep complexity is revealed where commercial motives, varied stakeholder motivations and fan passion can drive deleterious consumption choices by both athletes and sport consumers. A potentially damaging pattern is formed where rising consumer expectations collide with athlete demands and endeavours to propagate a system where vulnerability is manifested.

It is posited that sport consumers, as part of the sport system, are not only culpable for co-creating an increasingly problematic sport environment due to their demands, but in doing 
so have rendered themselves vulnerable as a result. The concept of consumer vulnerability has been described as "a state of powerlessness that arises from an imbalance in marketplace interactions or from the consumption of marketing messages and products” (Baker et al., 2005, p.7). An expanded perspective on consumer vulnerability suggests that it can be context specific and extends to consumers that do not have the ability or knowledge to make choices in their best interests, despite having the economic resources to do so (Shultz and Holbrook, 2009). In the context of the sport product, it appears to have evolved in a manner that reduces the power or ability of some consumers, particularly those who are highly engaged with sport or a sporting team, to pursue consumption goals and choices that benefit their well-being. Importantly, it is proposed that this concept of vulnerability extends to the athletes who also may suffer a reduced ability to make beneficial consumption choices, and in fact may engage in potentially risky behaviours, as a result of the pressures brought to bear by various stakeholders in the sport system, including consumer expectations of heightened levels of sport performance.

Given the wicked nature of this problem, and the duality it exposes in affecting both consumers and athletes, a multi-faceted approach to developing potential solutions is required. Our aim is to propose the use of a social marketing to address this wicked problem in sport, supported by a multi-theoretical approach that recognises a) the importance of diverse stakeholders; b) the need to co-create solutions with these stakeholders; and c) the dynamic nature of the sport system in which these stakeholders operate.

Stakeholder theory is a useful lens for identifying stakeholders and their motives, and is therefore relevant for developing efficiently resourced, robust social marketing interventions aimed at limiting wicked problems inherent in sport. While acknowledging that the nature of wicked problems may defy solutions, it is suggested that a multi-theoretical approach to social marketing may be valuable in tackling the problem from a holistic 
perspective. Social marketing has been defined as a "comprehensive, strategic and multifaceted marketing based approach to facilitate or maintain social good" (French and Gordon, 2015, p. 20). Strategic social marketing acknowledges the complex network of stakeholders and influences that impact on human behaviour and the need to engage this network in developing solutions to social problems that provide value for all stakeholders. As such, the application of stakeholder and systems theory, as well as the concept of value cocreation, can provide valuable insight in developing effective social marketing strategies to address wicked problems. Also relevant is the macro social marketing perspective which seeks to effect system wide change by tackling the institutional norms that propagate the problematic issues associated with sport. Macro social marketing focuses on change at a societal rather than individual level, however the latter can occur as a result of this broader transformation (Kennedy, 2015). From a managerial perspective, this paper provides valuable insight to a global sporting industry that commands billions of dollars in consumptive experiences but must be mindful of navigating the conflicting interests of its varied stakeholders.

This paper is organised as follows. First, a brief background is presented on the context of the modern sport environment in which the wicked problem has emerged. Next, the challenges faced by athletes are outlined demonstrating how they have rendered the athlete vulnerable to harmful consumption behaviours, both within and outside of sport. The equally vulnerable state of the sport consumer is then articulated. Finally, a multi-theoretical approach to social marketing is proposed to address the complex nature of this wicked problem. Given the intricate constellation of stakeholders embedded in the sport system, to effect behaviour change to improve societal outcomes requires a holistic focus across macro, meso and micro levels. These strategies should aim to effect change at the individual sport consumer level as well as the larger institutions and environment in which the wicked problem occurs. 


\section{Background and current sport environment}

Sport managers have long argued that their product is relatively unique and encumbered with a set of challenging characteristics. These include an ephemeral and experiential consumption and a highly variable and idiosyncratic market consisting of a myriad of stakeholders, many of which consider themselves highly invested through emotional attachment (Mullin, 1985). While Smith and Stewart (2010) revisited these characteristics and surmised that the industry had broadly stepped into line with general entertainment offerings, numerous challenges remain, including assessing and managing the impact that sport has within society as an amplification tool for various connected consumptive behaviours.

This argument for uniqueness in sport's operations is nuanced. While the management of sport can be aligned to a set of common business tools and practices (Hoye et al., 2008), the contextual nature of sporting activity is deeply ingrained in cultural and social practices that often go back centuries. These lead to an argument for the 'specificity of sport' as pronounced by the Nice Declaration on Sport (European Council, 2000) which recognised that sport goes well beyond a leisure or pastime and is a significant cultural institution in its own right, providing important social benefits to a wide range of communities. As Shank (2009, p.7) notes, "sport has become one of the most important and universal institutions in our society”, linking together industries, governments and consumers in mutually-beneficial, increasingly visible and highly valuable ways. These range from sport's mediating role as an avenue for social justice and facilitator of health through participation, right through to its attractive qualities for brand alignment and mass communication (Eime et al., 2013; Widdop et al., 2016).

Sport's modern commercial power is closely linked to its attractiveness to media operators seeking to satiate their commercial communication networks with desirable, live- 
action and immersive content (Hutchins and Rowe, 2012; Milne, 2016). These platforms, from established analogue players to new digital operators, see their audiences as networks of brands and consumers that can be parlayed together when an attractive product such as sport is on offer. As a result, despite the fragmentation of broadcast platforms, a plethora of sports are commanding increasingly strong sums for transmission rights (Evens et al., 2013).

By and large the sophistication of the industry is a conflux of marketing and management knowledge connecting desirable entertainment options (sport) to engaged consumers (sport fans and participants) who often act with enormous passion and high levels of involvement. Sport can, as a result, be addictive as a form of vicarious engagement with substantial power in creating high-levels of emotional identification that come replete with low-levels of demand elasticity (Krautmann and Berri, 2007). The cultural and societal entrenchment of sport adds further layers of complexity that provide a gamut of socially reflective and challenging issues, ranging from alcohol consumption, gambling association, gender equality, racism, role-modelling, social norms, the integrity of competition, and public spending priorities, that affect both consumers and athletes.

The highly-charged pervasiveness of sport is both commercially and socially desirable, but also is reflected in the levels of government and institutional connection to sport on a variety of levels. Sport as a purely athletic endeavour has no real 'owner' in a business sense, but merely a procession of custodians and stakeholders who seek to extract value from the role it plays in society. Governments therefore feel obliged to contribute as mediators, and typically are connected to sport in some way at all levels, from local councils and townships providing playing fields, state bodies funding events and major stadia and federal levels contributing to funding, policy and governance. Nestled in with these bodies are other layers of sport governing bodies and a plethora of administrative leagues and associations representing fans, participants and other stakeholders. 
The sport system with its complex network of stakeholders with both individual and interdependent goals brings with it key challenges. The premise of this paper is that this complex system has created: a) an environment which compels athletes to engage in risky consumption behaviours and b) that sport consumers are complicit in the increasing commercialisation of sport, which both exacerbates the pressures on athletes and which inflicts potentially harmful consumptive experiences (or vulnerability) on consumers themselves.

\section{Athlete Vulnerability in Sport}

Sport is an embodied performance genre that deifies and immortalizes the human condition. It represents a quintessential physical demonstration of 'natural drives' that are manifest in a spectacular collision of competition and corporeality. Faster, higher and stronger, as the Olympic ideal proclaims, stand alongside fortune, fame and favour. In evaluating this sociocultural phenomenon, it would be naïve to overlook the detrimental impacts of hypercompetitive sport (Denham, 2015). At the core of this sport-entertainment complex is a culture that lionizes success, lauds physical sacrifice, relishes violence, prescribes ideals of masculinity, resists gender equality, and embraces excess (Assael, 2007). It is a massmediated ritual through which dominant values, alluring myths and antiquated stereotypes are given centre stage (Gleaves and Llewellyn, 2013).

Integral to the culture of high performance sport are success, victory and dominance over others. These competitive drives bond team members and institutionalise rivalries. Hyper-professional sporting culture idealises the outer limits of physical capacity, where courage, risk, pain and aggression are idolised. As a result, athletes venture beyond established limits in their quest to achieve results that provide glory and — where possible - a massive pay cheque. A mythopoeiac expectation of success, combined with omertà-like 
loyalty to club and peers, has the capacity to compromise both ethical self-reflection and rational self-control (Andrews and Silk, 2012; Newman and Giardina, 2011). With profound external and internal pressures driven by consumers who expect ever-increasing levels of entertainment and achievement, leading athletes are easily seduced by virtually any new technology, training, supplement or substance that might enhance their capacity to perform and, by extension, to raise their standing in the sport-entertainment community.

It is not just fans demanding excellence. Coaches, journalists and the broader sporting system of teams, leagues, administrators, broadcasters sponsors and commercial partners insist on what is (for most athletes) unsustainable levels of achievement, yet at the same time emphasise that failure is unacceptable. Disciplines such as elite cycling, for example, embrace cutting edge medical and scientific support, including essential contributions from physicians, support therapists, sport scientists, bio-mechanists and engineers (Brissonneau, 2006; Waddington and Smith, 2008). As a result of such pressures, athletes find themselves in a sporting environment where medical treatments and substances to enhance recovery and sustain performance are promoted as never before. Based on a meta-analysis of available international studies, more than 90 per cent of all people who play sport, irrespective of performance level, have used some form of performance enhancing substances (PES) to pursue a competitive benefit at some time in their sporting lives (Stewart and Smith, 2014). In fact, for athletes in receipt of PES, their first experience is most often from a trusted source (Laure and Binsinger, 2005).

Further, since coaches and managers have a vested interest in getting injured athletes back on the field of play in the shortest possible time to satiate the needs of consumers and the sporting commercialism they drive, doctors are under an implied pressure to admit permitted—and sometimes banned—pain-killing and anti-inflammatory drugs to accelerate that process. A suite of studies on the impact of commercial incentives on athletes' 
behaviours have highlighted 'win at all costs' behavioural consequences, from the ruthless pursuit of lucrative sponsorships to an obsessive experimentation with training technologies and recovery modalities (Bairner, 2003; Belk, 1996; Gems, 1999; van Bottenburg, 2003).

Since professional sport is heavily organised around revenue opportunities, market conditions can further influence the normative behaviour of athletes (Li et al., 2001), whereupon the use of PES becomes routine (Aghion and Williamson, 1999). Elite athletes have reported that in order to reach the highest levels of performance it is necessary to go beyond “naturally evolved talent” by strategically employing PES (Cooper, 2012, p. 22). For example, in road cycling it has been widely acknowledged that some "serious" substance use was needed to remain "in the saddle” (Jeukendrup and Tipton, 2009, p. 186; Jones, 2010). Lentillon-Kaestner and Carstairs (2010, p. 338) found that "all of the young cyclists ... took some [banned] products to improve their performance", and it was widely believed that it "would not be possible to perform ... without their use” (p. 342). Athletes from the lower levels of sport have indicated that in order to transition to the next level, additional PES use would be essential because at the professional and elite ranks it was assumed that "anything goes” (Lentillon-Kaestner and Carstairs, 2010, p. 342). Based on this research, it appears that many athletes will experiment with almost any substance-banned or legal—if they believe it will improve their performances (Smith et al. 2010; Wiefferink et al., 2008).

With performance connected to so many seemingly desirable incentives, athletes are known to seek out ways in which to accommodate or deflect attainment pressures. For many decades, alcohol consumption has been used to manage the stresses associated with maintaining peak levels of performance (Buti and Fridman, 2001; Laure et al., 2004), especially for male athletes (Peretti-Watel et al., 2002). This was aligned with a sport culture that emphasised a 'work hard, play hard' ethos (Stewart et al., 2004) as well as a 'hypermasculine' ideal that disregards some forms of anti-social behaviour such as gambling and 
aggression (Fincoeur et al., 2013; Stewart and Smith, 2014). Perhaps it is no surprise that, in an effort to ‘escape’ from the pressure cooker existence of professional sport, some athletes have resorted to illicit drugs such as cannabis, cocaine and ecstasy. Other research has revealed a linear causality between competitive pressures and psychological, social and economic returns (Wenner 1998; Wilson 1990; Wright 1999). According to Waddington (2000, p.4), "sport is played for higher, sometimes much higher stakes, whether these be economic, political-national, personal or a combination of all three.” Commercialisation has ostensibly created a market in which an athlete's rewards will mirror his or her performance (Stewart, 2007).

In essence professional sport has workplace constraints and community expectations that make it a uniquely complex and contradictory environment for athletes (Volkwein, 1995). They are required to be exemplary performers on the field and, whether they like it or not, 'role models' in society off the field (Parry, 2009). In order to achieve this, sport organisations survey and micro-manage athletes’ working lives, and purposefully intrude into their private lives (Zaksaite, 2012). The media glorifies those who succeed on the field, but have an almost perverse interest in the lives of players off the field, particularly if these details can form some form of 'inside story' on troubled behaviours (Rojek, 2006). A salacious media can willingly exaggerate public outrage at the imperfections of athletes, using social media to instantly cast aspersion, innuendo and supposed community values (Smith and Stewart, 2012). Athletes need to manage risk and compliance as never before. The workplace culture of professional sport places enormous constraints over exercise, diet and personal responsibility for following increasingly complex rules. Concurrently, there are expectations from the community to win, to show character under pressure, to lose graciously, and to be a source of admiration both in and outside of sport (Hamilton and Coyle, 2012). Above all consumers want higher levels of achievement, their desire for sport's 
intoxicating competitive juices and the eustress it produces insatiable. With such heightened expectations is it any wonder that many athletes can fall from that lofty pedestal?

\section{Consumer vulnerability in sport}

The previous section describes how the collective actions of consumers and other key stakeholders, such as sport owners and managers as well as the media, have co-created a system that encourages athletes to engage in a range of harmful behaviours. However, this system does not just put athletes in a vulnerable situation; it also has the potential to harm the consumers that have contributed to its development. Various elements of the sport consumption experience may contribute to the emergence of consumer vulnerability, including fan identification with sport teams, the motivation for sport consumption and the influence of endorsements made by professional athletes.

Team identification is the degree to which an individual's sense of self becomes vested in their sports team (Wann, 2006). A fan with a high level of identification, for instance, will feel a heightened sense of belonging and attachment to their team (Wann and Branscombe, 1993) and will base their self-esteem, in part, on how their team performs (Wann et al., 2001). In light of this phenomenon, it is perhaps unsurprising to note that fans with higher levels of team identification tend to have greater recognition of, knowledge about, and more positive attitudes and satisfaction towards team sponsors (Fink et al., 2009; Gwinner and Swanson, 2003). For example, Madrigal (2003) found that high team identification was associated with greater purchase intentions towards the products of the sponsoring brand. Unfortunately, and as alluded to earlier, many sports teams have developed sponsorship arrangements with brands of risky products that, if over-consumed, could give rise to consumer harms (Maher et al., 2006; Lindsay et al., 2013). High levels of team identification may consequently lay the foundation for consumer vulnerability by increasing 
their propensity to purchase goods that are inconsistent with the pursuit of health and wellbeing. For example, and on the basis of this theorizing, if a team were to develop a sponsorship arrangement with a fast food retailer, an individual who identified highly with that team will increase their consumption of this product.

Wann (1995) identified both eustress and the entertainment value of sport as central motivations for becoming a sports fan. By itself, entertainment as a motivation is relatively innocuous in that it is relevant to other recreational pastimes that consumers may adopt, such as seeing a movie or attending an amusement park (Wann, 1995). However, its combination with eustress elevates it to a far more potent level where more complex levels of attraction and arousal are activated. Eustress is described as “the human need for positive stress and psychological arousal”' (Smith and Stewart, 2007, p.158). In essence, it is a conflation of pleasure and anxiety, which are common emotions linked to the sport fan experience given the inherent connection to other fans, athletes, competitive tensions and unpredictable outcomes that exist (Stavros et al., 2014).

These interrelated motivations can render consumers vulnerable when potentially harmful products are promoted as a means for further enhancing the entertainment, attractiveness and arousing experience of sport consumption. Increasing commercialisation has fostered greater promotional and sponsorship arrangements with 'risky’ products which amplifies consumer exposure and support of unhealthy food, alcohol and gambling (e.g., Biscaia et al., 2013). Not only is the promotion of these products visible during live or televised viewing of sporting matches and events, they are often consumed as part of a blended sport experience.

Two notable examples are gambling and alcohol, products frequently consumed alongside a sporting event as a means of enhancing the entertainment value of those events (Gee et al., 2013; Monaghan and Derevensky, 2008). Not surprisingly therefore these 
industries are also the two most common sponsors of professional sporting leagues and teams (Bestman et al., 2015; Maher et al., 2006; McKelvey, 2004). The pursuit of entertainment and the attraction of eustress through sport has the potential to predispose sports fans to products or services that, if over consumed, may prove detrimental to their health and wellbeing.

Consumer vulnerability may also occur as a result of the influence of endorsements made by professional athletes (Peetz et al., 2004; Veltri et al., 2003). Professional athletes are often portrayed as modern-day heroes or role models that possess various social or physical ideals (Lines, 2001), and these portrayals shape the symbolic meanings that become attached to those athletes (Darnell and Sparks, 2007). When athletes endorse a product, these meanings are transferred from the athlete to the product and ultimately have the effect of influencing how consumers perceive the product (see McCracken, 1989). Consumer vulnerability may consequently occur when products with the potential to cause harm are endorsed by athletes that are revered. For instance, consumer attitudes towards, and consumption of, energy dense and nutrient poor food items tends to increase when those items are endorsed by a sports celebrity (Boyland et al., 2013; Dixon et al., 2011). Thus, while professional athletes are usually associated with ideals such as physical fitness and health, the product endorsements may paradoxically promote the very antithesis of such lifestyles (Cornwell, 2008). Countering such an outcome is fraught with considerable difficulty. While some countries have prohibited sporting linkages with certain products alcohol in France for example - the global marketing actions and activities of current or recently retired athletes for product endorsement is rampant.

\section{Summary of the wicked problem and implications for the role of social marketing}

The sports landscape is a dynamic system; an ecology that is impermanent and always evolving in response to forces such as globalisation and commercialisation, and internal 
interactions among multiple and diverse stakeholders - and this is at the very heart of this wicked problem. These interactions are often simultaneous, reciprocal and may even be fraught with tensions derived from misaligned priorities and asymmetric transparency both among and between parties. While it has been acknowledged that a definitive solution to a wicked problem is unlikely, "partial and provisional responses” are realistic and can help manage complex situations (Head and Alford, 2015, p. 733). As will be outlined in this section, social marketing lends itself to addressing complex, or wicked, social problems that are influenced by broader environmental contexts and feature multiple stakeholders. The key differentiating factor between social marketing and other types of social intervention is its marketing lens and consequently its focus on "social value creation through the exchange of social offerings” (French and Russell-Bennett, 2015, p. 149). This approach therefore seems appropriate in challenging existing behaviours and vulnerabilities that have emerged in sport largely as a result of a broader commercial marketing context. Further, we suggest that the effectiveness of social marketing can be enhanced by considering a multi-theoretical approach in designing solutions to wicked problems. There have been calls to extend theory use in social marketing beyond traditional sociological and psychological perspectives, and to take a macro-level outlook incorporating multiple stakeholders (Buyucek et al., 2016; Gordon and Gurrieri, 2014; Hoek and Jones, 2011; Rundle-Thiele, 2013). We propose that adopting perspectives from stakeholder theory, systems theory and the concepts of value creation and co-creation are both useful and complementary in addressing the challenges of the wicked problem of athlete and consumer vulnerability within the sport system.

Stakeholder theory recognises the importance of a network of stakeholders in the performance of an organisational entity. Proponents of this theory state that the organisation's primary economic and social responsibility is to generate a positive return in terms of creating benefits for, and satisfying the needs of, its key constituents (e.g., Bouckaert and 
Vandenhove, 1998; Rowley, 1997). Stakeholders include both organisations and individuals who can influence and be affected by an organisation's actions (Freeman, 1999), however they can have disparate or even conflicting expectations (Jawahar and McLaughlin, 2001). While stakeholder management requires the "simultaneous attention to the legitimate interests of all stakeholders" (Donaldson and Preston, 1995, p.67), it is acknowledged that an organisation must prioritise and serve the needs of its most critical stakeholders to ensure their ongoing support. Hult et al. (2011) identify six stakeholder groups of interest to marketers: customers, suppliers, employees, regulators, shareholders and the local community. Managing these multiple groups is challenging. A narrow focus on customers or shareholders is often adopted due to the limitations of an organisation's resources; however a broader view of stakeholders, as encompassing almost anyone including influencers such as competition, media and the government, becomes complex and impractical to manage (Mitchell, Agle and Wood, 1997). Stakeholder analysis can be used to identify stakeholders, their claims, motivations and relative importance, by evaluating the salient stakeholders’ levels of power, legitimacy and urgency related to the issue (Mitchell et al., 1997). Social marketers need to identify which stakeholders are integral to the success of a social marketing initiative, or could threaten its success, and the extent to which they could influence other stakeholder groups. It is critical to acknowledge that these levels of power, legitimacy and urgency may vary over time among different stakeholders, in response to different issues and priorities (Friedman et al., 2004). Consistent with the key principles of social marketing, stakeholder analysis should be informed by formative research designed to capture insights into the differing attitudes, motivations and decision making processes (French and Gordon, 2015).

Some researchers have suggested that an individual or group is only a stakeholder when they are somehow “at risk” in relation to organisational activity (Clarkson, 1995) and 
therefore can include any individual or group who is harmed. Polonsky and Ryan (1996) apply stakeholder theory to evaluate the types of harm that evolve along the diverse aspects of the chain in a social marketing setting. The authors argue that by identifying and targeting specific stakeholders, understanding of the negative consequences of exchanges can be overlaid across key social problems and more diverse stakeholders. The web of stakeholders can be categorised according to those who cause harm, those who are harmed and those who can assist with limiting the harm (Polonsky and Ryan, 1996). It is important to note that these groups may not be mutually exclusive, adding to the complexity of the system (Carrigan, 1996). This is a holistic approach, given that the harm chain incorporates the interests of all relevant stakeholders and has been applied to several social marketing problems including environmental protection and anti-smoking (Polonsky and Ryan, 1996). In the sports context, a harm chain may involve a range of stakeholders, for example, athlete transgressions may harm the team, the sport, sponsoring brands, the fans and community. Applying stakeholder theory requires strategy development only after the members of the network have a clear understanding of the various interdependent connections (i.e., how the connections create harm as well as value) across all stakeholders (Greenley and Foxall, 1996; Polonsky, 1996).

In exploring the extent of stakeholder involvement in the context of interventions aimed at limiting harmful alcohol consumption, Buyucek et al. (2016) distinguish stakeholder theory from other complementary perspectives relevant to social marketing including systems thinking and co-creation. The authors advocate for the integration of a multi-stakeholder approach in downstream interventions which can guide and complement co-creation and systems based approaches by identifying and prioritising relevant actors in the system and working closely with them to design, plan and implement social marketing initiatives. Essentially stakeholder theory can act as a useful framework for assisting social marketers to manage the relationships in the system effectively across different forms of partnership. 
These include alliances (Temple et al., 2008), initiatives (Hastings et al., 2002), coalitions (Singer and Kayson, 2004), partnerships (French and Gordon, 2015) and stakeholders (e.g., Domegan, 2013). The recent interest in the network view of marketing explicitly adopts a stakeholder perspective by recognising that effective management of complex networks and their incumbent interdependency creates long-term strategic advantage. Therefore, the overall success of the exchange network is dependent on the actions of all members, rather than on the actions of one member or a single exchange (Wilkinson and Young, 2002).

Aligned with stakeholder theory, Brennan, Previte and Fry (2015) propose a Behavioral Ecological Model to underpin social marketing. This model recognises and reflects the systems perspective and the interrelated need to examine the complex relational behaviours among stakeholder groups rather than individuals. This systems lens acknowledges that individual behaviour occurs within the context of historical, cultural, social, physical and environmental settings. The relational approach embedded here reflects a stakeholder perspective and ensures that subtle, interactive relationships in the market are captured and that both value creation and barriers to creation are identified and addressed. For example, the macro-system may include public policy, laws and regulations and societal systems. In the context of the wicked problem in sport, the individual behaviour and vulnerability of consumers and athletes occurs within this larger system which facilitates and enables this behaviour through cultural expectations, regulations concerning sponsorship and accessibility and acceptability of performance enhancing substances or products such as alcohol. At the meso-system level is the sport system itself which includes sporting bodies and governance systems, individual sport clubs, sponsors and even the media, all of which may have expectations and commercial priorities which run contrary to the interests or wellbeing of other stakeholders such as sport consumers and athletes. At the micro-system level is the individual behaviour of athletes and fans and that of their immediate peer groups. A social 
marketing approach cannot simply focus on one stakeholder group, for example athletes, without acknowledging the interaction and interrelationships between other groups within the system (Lefebvre, 2012).

The importance of a systems perspective has been highlighted in the context of understanding and coordinating systemic change across groups of individuals required to tackle complex or wicked social problems which are increasingly the focus of social marketing (Domegan et al., 2016; French and Gordon, 2015; Kennedy, 2015). Domegan et al. (2016, p.1127) argue for a systems perspective in social marketing that focuses on "top down, bottom up connections and relational approaches among all participants within the defined micro, meso and macro system.” Insight into all three system levels, and their “reciprocal influence”, is needed to provide a holistic understanding of the system and guide effective social marketing initiatives (Luca, Hibbert and McDonald, 2016, p.1145). Stakeholder theory enables this systems notion to embrace multiple perspectives, from identifying the issue, to comprehending its impacts and solutions. Inclusion of stakeholders in all stages of social marketing initiatives including intervention planning, implementation, and evaluation stages may enhance marketing outcomes (Buyucek et al., 2016). The community setting of sports can certainly be classified as a complex, dynamic system, given the plethora of stakeholders and the interactions between them. For example, in relation to the issue of doping in sport, stakeholders include the federal government, coaches, athletes, administrators in the sport, owners, fans, community, media, sponsors and charitable partners, all lobbying for reconciliation of often divergent needs. The tension between fans' demands for increasingly high performance and entertainment and athletes' limits in delivering is at the heart of a system failure, when athletes are tempted to cheat to meet the expectations of other stakeholders. The ecosystem of sport can therefore be conceived as an enmeshed network in which each constituent is a stakeholder in other stakeholders' systems (Rowley, 1997). The 
identification of the members within an organisation's environment is at the core of this perspective. Post et al. (2002) believe that firms must recognise the multiplicity and diversity of relationships and that any stakeholder can be critical, at any one particular time, with regards to a particular issue. Influencing major social change necessitates focusing on whole communities as spaces of intervention (Farquhar et al., 1985).

Previous stakeholder commentary has overlooked the bilateral nature of responsibility among parties in the system. Fassin (2012) suggests that the question of stakeholder influence can be framed as one of reciprocity, with stakeholders treating each other in a fair and responsible way and defines genuine stakeholders as loyal partners with mutually beneficial vision and objectives. This concept of stakeholder reciprocity aligns with the macro-social marketing and the systems perspective, given that these "micro" relationships simultaneously exist and mutually influence and interact in the context of the larger sports ecosystem. Kennedy (2015) suggests that enacting system level change of influential norms and institutions requires a partnership approach with key stakeholders to educate and influence, however it is also acknowledged that legislation may be required to further motivate or support this change.

Once system stakeholders are identified, addressing the wicked problem in sport requires an understanding of how to entice constituents into acting to facilitate not only individual well-being, but also the greater good. Changing or influencing behaviour is an incremental process that must consider people’s “current realities” and how a change in behaviour is relevant or beneficial to them (Lefebvre, 2011, p. 61). Social marketing requires an understanding of the concept of exchange, that is, what the individual stakeholder or stakeholder group needs to do and how they will benefit (French and Blair-Stevens, 2006). Further, social marketers need to adopt a relational approach, as opposed to transactional, to working with a range of stakeholder groups to engender sustainable social change that 
focuses not only on the individual but the wider context influencing their behaviour (Hastings, 2003).

Aligned with this thinking is the concept of value cocreation, a central tenet of service-dominant (S-D) logic (Vargo and Lusch, 2008; 2016). The value cocreation process involves the organisation developing value propositions with the customer or beneficiary determining value upon consumption of a good or service (Payne, Storbacka and Frow, 2008). Value propositions are reciprocal in nature and value cocreation is an interactive, experiential and relational process (Ballantyne et al., 2011). Evolving thought in S-D logic has recognised the role of the broader "value network" of suppliers and other social and economic actors, or stakeholders, that contribute to the value cocreation process (Lusch, Vargo and Tanniru, 2010, p.20). According to the most recent update and extension of S-D logic, moving from a dyadic to a network perspective, Vargo and Lusch (2016, p. 8) propose the axiom that "Value is co-created by multiple actors, always including the beneficiary." Facilitating value cocreation requires communication to develop common ground and invite collaboration, relational efforts to form social bonds and finally, the sharing of information to allow each actor or stakeholder to achieve their goals (Neghina et al., 2015).

The applicability of the value cocreation perspective also has been recognised in the context of social marketing. For example, Lefebvre (2012, p. 121) suggests that social marketing should focus on facilitating the cocreation of value in which individuals are seen as “co-producers or collaborators in adopting new behaviors or in quitting other ones, rather than as targets.” Domegan et al. (2013) have undertaken a critical exploration of the potential for the adoption of value cocreation in social marketing, highlighting both its compatibility as well as potential obstacles for social marketers. The authors suggest that social marketers need to understand what is of value to individuals and other stakeholders, work with these audiences to create value propositions and adopt a cocreative process to realise this value. 
Essentially this approach advocates the need for "people becoming direct and active participants in social change”, as the reason behind the failure of many social marketing initiatives is the lack of stakeholder engagement in developing value propositions (Domegan et al., 2013, p. 241). The authors further propose that a value cocreation approach applied to social marketing would be iterative, with collaborative processes that would give relevant stakeholders a voice in defining the issue and co-designing initiatives or interventions which would then require a coordinated system of co-delivery. While this perspective presents new opportunities for working with stakeholders and enhancing the effectiveness of social marketing strategies, Domegan et al. (2013) also identify a number of challenges including the ideological compatibility with social marketing in relation to the concept of value and the potential for this approach to result in compromise given the complexity of the context in which social marketers operate. However, emerging research has begun to provide insight into the application of value cocreation in a social marketing context (e.g., Luca et al., 2016; Zainuddin, Russell-Bennett, Previte, 2013).

Value cocreation may be a useful perspective to adopt in tackling the wicked problem of athlete and consumer vulnerability in sport. There is increasing recognition of the importance of collaboration and interaction between not only the fan/team dyad but also between other groups of stakeholders that form the sport value network (Woratschek, Horbel and Popp, 2014). That is, sport operates within a system where various actors, or stakeholders, work together to achieve mutually beneficial outcomes through interactions and the sharing of knowledge and other cultural resources. As such, sport should be regarded as a platform where different actors cocreate value within a network (Woratschek et al., 2014). However, understanding what is of value to each group is challenging and stakeholder groups may not necessarily be homogeneous, despite sharing a common interest. For example, sport consumers represent a diverse population from a socio-demographic perspective and can be 
segmented further on a spectrum of involvement with sport, from fanatics to casual spectators (Hunt et al., 1999). Consistent with key tenets of social marketing (French and Blair-Stevens, 2006), a robust customer-oriented and segmented approach is required to stimulate behaviour change, not only among different stakeholder groups, but also within groups.

\section{Conclusion}

This paper is the first to articulate the wicked problem of athlete and consumer vulnerability in sport and to explore the potential role for a multi-theoretical approach to social marketing in mitigating this problem. The context of sport provides unique insight into the understanding of wicked problems in consumer research by exploring a complex social problem in which the consumer is both complicit in, and made vulnerable by, the problem. Further this concept of consumer vulnerability in sport extends to the athletes who are compelled by the nature of the sport system to engage in unhealthy behaviours. Social marketing has emerged as a discipline which recognises the complexity of social problems and the need to engage and collaborate with multiple stakeholders at various levels of the social, economic and marketing systems. Further, the concept of value cocreation may provide insight into the interactions and processes within the sport system that formulates value for the various stakeholders, or conversely introduces harm or vulnerability for some actors. While wicked problems by their nature cannot be readily solved, this paper advocates the efficacy of a social marketing approach, supported by insights from stakeholder theory, systems theory and value cocreation. 


\section{References}

Aghion, P. and Williamson, J. (1999), Growth, Inequality and Globalization: Theory, history and policy, Cambridge University Press, Cambridge.

Andrews, D. and Silk, M. (Eds.). (2012), Sport and neoliberalism: Politics, consumption, and culture, Temple University Press, Philadelphia.

Assael, S. (2007), Steroid nation, ESPN Books, New York.

Bairner, A. (2003), “Globalization and sport: The nation strikes back”, Phi Kappa Phi Forum, Vol. 83 No. 4, pp. 34-37.

Baker, S.M., Gentry, J.W. and Rittenburg, T.L. (2005), "Building understanding of the domain of consumer vulnerability”, Journal of Macromarketing, Vol. 25 No. 2, pp. 128-139.

Ballantyne, D., Frow, P., Varey, R.J. and Payne, A. (2011), "Value propositions as a communication practice: taking a wider view”, Industrial Marketing Management, Vol. 40, pp. 202-210.

Belk, R. (1996), “Hyperreality and globalization: Culture in the age of Ronald McDonald”, Journal of International Consumer Marketing, Vol. 8 No. 3, pp. 23-37.

Bestman, A., Thomas, S.L., Randle, M. and Thomas, S.D. (2015), “Children’s implicit recall of junk food, alcohol and gambling sponsorship in Australian sport”, BMC Public Health, Vol. 15 No. 2, pp. 1022.

Biscaia, R., Correia, A., Ross, S.D. and Rosado, A.F. (2013), “Sponsorship effectiveness in professional sport: An examination of recall and recognition among football fans”, International Journal of Sports Marketing and Sponsorship, Vol. 16 No.1, pp. 7-23.

Bloodworth, A. and McNamee, M. (2010), “Clean Olympians: Doping and anti-doping: The views of talented young British Athletes”, International Journal of Drug Policy, Vol. 21 No. 3, pp. 276-282. 
Bouckaert, L. and Vandenhove, J. (1998), "Business ethics and the management of non-profit institutions”, Journal of Business Ethics, Vol. 17 No.9-10, pp. 1073-1081.

Boyland, E.J., Harrold, J.A., Dovey, T.M., Allison, M., Dobson, S., Jacobs, M.C. and Halford, J.C. (2013), “Food choice and overconsumption: effect of a premium sports celebrity endorser”, Journal of Pediatrics, Vol. 163 No. 2, pp. 339-343.

Brennan, L. Previte, J. and Fry, M-L., (2016), “Social marketing’s consumer myopia”, Journal of Social Marketing, Vol. 6 No. 3, pp. 219-239.

Brissonneau, C. (2006), “Deviant Careers: The case of cycling”, in Ethics and Social Science Research in Anti-Doping, WADA Conference, Larnaca, Cyprus, pp. 13-14.

Buyucek, N., Kubacki, K., Rundle-Thiele, S. and Pang, B. (2016), “A systematic review of stakeholder involvement in social marketing interventions”, Australasian Marketing Journal, Vol. 24 No. 1, pp. 8-19.

Buti A. and Fridman S. (2001), Drugs, Sport and the Law, Scribblers Publishing, Mudgeeraba.

Carrigan, M. (1995) "POSIT-ive and negative aspects of the societal marketing concept: Stakeholder conflicts for the tobacco industry”, Journal of Marketing Management, Vol. 11 No. 3, pp. 469-485.

Conklin, J. (2006), Dialogue mapping:building shared understanding of wicked problems. Chichester, England: Wiley Publishing.

Cornwell, B.T. (2008), "State of the art and science in sponsorship-linked marketing”, Journal of Advertising, Vol. 37 No. 3, pp. 41-55.

Darnell, S.C. and Sparks, R. (2007), “Meaning transfer in sports news and sponsorship: Promoting Canadian Olympic triathlete Simon Whitfield”, International Journal of Sports Marketing and Sponsorship, Vol. 8 No. 2, pp. 44-63.

Denham, B. (2015), “Drug use in baseball”, in Moller, V., Waddington, I. and Hoberman, J. 
(Eds), Routledge Handbook of Drugs and Sport, Routledge, London, pp. 78-88.

Dixon, H., Scully, M., Wakefield, M., Kelly, B., Chapman, K. and Donovan, R. (2011), "Parent's responses to nutrient claims and sports celebrity endorsements on energydense and nutrient-poor foods: an experimental study”, Public Health Nutrition, Vol. 14 No. 6, pp. 1071-1079.

Domegan, C., McHugh, P., Devaney, M., Duane, S. et al. (2016), “Systems thinking social marketing: conceptual extensions and empirical investigations”, Journal of Marketing Management, Vol. 32 No. 11/12, pp. 1123-1134.

Domegan, C., Collins, K., Stead, M., McHugh, P. and Hughes, T. (2013). “Value co-creation in social marketing: functional or fanciful?” Journal of Social Marketing, Vol.3 No. 3, pp. 239-256.Donaldson, T. and Preston, L.E. (1995), “The stakeholder theory of the corporation: concepts, evidence and implications”, Academy of Management Review, Vol. 20 No. 1, pp. 65-91.

Eime, R.M., Young, J.A., Harvey, J.T., Charity, M.J. and Payne, W.R. (2013), “A systematic review of the psychological and social benefits of participation in sport for adults: Informing development of a conceptual model of health through sport”, International Journal of Behavioral Nutrition and Physical Activity, Vol. 10, pp. 135.

European Council. (2000), Nice declaration: Declaration on the specific characteristics of sport and its social function in Europe, European Council, Nice.

Evens, T, Iosifidis, P. and Smith, P. (2013), The political economy of television sports rights, Palgrave Macmillan, London.

Farquhar, J.W., Fortmann, S.P., Maccoby, N., Haskell, W.L., Williams, P.T., Flora, J.A., . . . Hulley, S.B. (1985), “The Stanford five-city project: Design and methods”, American Journal of Epidemiology, Vol. 122 No. 2, pp. 323-334. 
Fassin,Y. (2012), “Stakeholder management, reciprocity and stakeholder responsibility”, Journal of Business Ethics, Vol. 109 No.1, pp. 83-96.

Fincoeur B., Frenger M. and Pitsch W. (2013), “Does one play with the athletes' health in the name of ethics?” Performance Enhancement \& Health, Vol. 2 No. 4, pp. 182-193.

Fink, J. S., Parker, H. M., Brett, M. and Higgins, J. (2009), “Off field behaviour of athletes and team identification: Using social identity theory and balance theory to explain fan reactions”, Journal of Sports Management, Vol. 23, pp. 142-155.

Freeman, R. E. (1999), “Divergent stakeholder theory”, Academy of Management Review, Vol. 24 No. 2, pp. 233-236.

French, J. and Gordon, R. (2015), Strategic Social Marketing, SAGE Publishing, London.

French, J. and Blair-Stevens, C. (2006), National Social Marketing Benchmark Criteria, National Social Marketing Centre, London.

French, J. and Russell-Bennett, R. (2015), “A hierarchical model of social marketing”, Journal of Social Marketing”, Vol. 5 No. 2, pp. 139-159.

Friedman, M.T., Parent, M.M. and Mason, D.S. (2004), “Building a framework for issues management in sport through stakeholder theory”, European Sport Management Quarterly, Vol. 4 No. 3, pp. 170-190.

Gee, S., Jackson, S. and Sam, M. (2013), The culture of alcohol promotion and consumption at major sports events in New Zealand, Research report commissioned by the Health Promotion Agency, Wellington.

Gems, G. (1999), “Sports, war, and ideological imperialism”, Peace Review, Vol. 11 No. 4, pp. 573-578.

Gleaves, J. and Llewellyn, M. (2013), “Sport, drugs and amateurism: Tracing the real cultural origins of anti-doping rules in international sport”, The International Journal of the History of Sport, Vol. 31 No. 8, pp. 839-853. 
Gordon, R. and Gurrieri, L. (2014), “Towards a reflexive turn: social marketing assemblages”, Journal of Social Marketing, Vol. 4 No. 3, pp. 261-278.

Greenley, G. and Foxall, G.R. (1996), “Consumer and nonconsumer stakeholder orientation in UK companies”, Journal of Business Research, Vol. 35 No. 2, pp. 105-116.

Gucciardi, D., Jalleh, G. and Donavan, R. (2010), “Does social desirability influence the relationship between doping attitudes and doping susceptibility in athletes?” Psychology of Sport and Exercise, Vol. 11 No. 6, pp. 479-486.

Gwinner, K. and Swanson, S. (2003), “A model of fan identification: Antecedents and sponsorship outcomes”, Journal of Services Marketing, Vol. 17 No. 3, pp. 275-94.

Hamilton, T. and Coyle, D. (2012), The secret race: inside the hidden world of the Tour de France: Doping, cover ups, and winning at all cost, Transworld Publishers, London. Hastings, G. (2003), “Relational paradigms in social marketing”, Journal of Macromarketing, Vol. 23 No. 1, pp. 6-15.

Hastings, G., Stead, M., and MacKintosh, A.-M., (2002), “Rethinking drugs prevention: radical thoughts from social marketing”, Health Education Journal, Vol. 61 No. 4, pp. $347-364$.

Head, B.W. and Alford, J. (2015), "Wicked problems: Implications for public policy and management”, Administration and Society, Vol. 47 No. 6, pp. 711-739.

Hoek, J. and Jones, S.C. (2011), "Regulation, public health and social marketing: a behaviour change trinity”, Journal of Social Marketing, Vol. 1 No. 1, pp. 32-44.

Holt, N.L., Tamminen , K.A., Tink, L.N. and Black, D.E. (2009), “An interpretive analysis of life skills associated with sport participation”, Qualitative Research in Sport and Exercise, Vol 1 No. 2, pp. 160-175. 
Hoye, R., Nicholson, M. and Smith, A. (2008), “Unique aspects of managing sport organizations”, in Wankle, C. (Ed.), Sage Handbook of 21st Century Management, Sage Publications, London, pp. 501-509.

Hult, G.T.M., Mena, J.A., Ferrell, O.C. and Ferrell, L. (2011), “Stakeholder marketing: a definition and conceptual framework”, Academy of Management Science Review, Vol. 1, pp. 44-65.

Hunt, K. A., Bristol, T, and Bashaw, R. E. (1999), “A conceptual approach to classifying sports fans”, Journal of Services Marketing, Vol. 13 No. 6, 439-452.

Hutchins, B. and Rowe, D. (2012), Sport beyond television. The Internet, digital media and the rise of networked media sport, Routledge, New York, NY.

Jawahar, I.M. and McLaughlin, G.L. (2001), “Toward a descriptive stakeholder theory: an organizational lifecycle approach”, Academy of Management Review, Vol. 26 No. 3, pp. 397-414.

Jeukendrup, A. and Tipton, K.D. (2009), “Legal nutritional boosting for cycling”, Current Sports Medicine Reports, Vol. 8 No. 4, pp. 186-191.

Jones, C. (2010), “Doping in cycling: Realism, antirealism and ethical deliberation”, Journal of the Philosophy of Sport, Vol. 37 No. 1, pp. 88-101.

Kennedy, A-M. (2015), “Macro-social marketing”, Journal of Macromarketing, doi:10.1177/0276146715617509.

Krautmann, A.C. and Berri, D.J. (2007), “Can we find it at the concessions? Understanding price elasticity in professional sports”, Journal of Sports Economics, Vol. 8 No. 2, pp. 183-191.

Laure P., Lecerf T., Friser A. and Binsinger C. (2004), “Drugs, recreational drug use and attitudes towards doping of high school athletes”, International Journal of Sports Medicine, Vol. 25 No. 2, pp. 133-138. 
Laure, P. and Binsinger, C. (2005), “Adolescent athletes and the demand and supply of drugs to improve performance”, Journal of Sports Science Medicine, Vol. 4 No. 3, pp. 272277.

Lefebvre, R.C. (2012), “Transformative social marketing: cocreating the social marketing discipline and brand”, Journal of Social Marketing, Vol. 2 No. 2, pp. 118-129.

Lefebvre, R.C. (2011), “An integrative framework for social marketing”, Journal of Social Marketing, Vol. 1 No. 1, pp. 54-72.

Lentillon-Kaestner, V. and Ohl, F. (2011), “Can we accurately measure the prevalence of doping?” Scandinavian Journal of Medicine and Science in Sport, Vol. 21, pp. 132142.

Li, M., Hofacre, S. and Mahony, D. (2001), Economics of Sport, Fitness Information Technology, West Virginia.

Lindsay, S., Thomas, S., Lewis, S., Westberg, K., Moodie, R. and Jones, S. (2013), “Eat, drink and gamble: Marketing messages about 'risky’ products in an Australian major sporting series”, BMC Public Health, Vol. 13 No.1, pp. 719-730.

Lines, G. (2001), "Villains, fools or heroes? Sports stars as role models for young people”, Leisure Studies, Vol. 20 No. 4, pp. 285-303.

Luca, N., Hibbert, S. and McDonald, R. (2016), "Midstream value cocreation in social marketing”, Journal of Marketing Management, Vol. 32 No. 11/12, pp. 1145-1173.

Lusch, R.F., Vargo, S.L. and Tanniru, M. (2010), “Service, value networks and learni”, Journal of the Academy of Management Science, Vol. 38, pp. 19-31.

Madrigal, R. (2003), “Investigating an evolving leisure experience: Antecedents and consequences of spectator affect during a live sporting event”, Journal of Leisure Research, Vol. 35 No. 1, pp. 23-48. 
Maher, A., Wilson, N., Signal, L. and Thomson, G. (2006), "Patterns of sports sponsorship by gambling, alcohol and food companies: An internet survey”, BMC Public Health, Vol. 6 No. 1, pp. 1.

McCracken, G. (1989), "Who is the celebrity endorser? Cultural foundations of the endorsement process”, Journal of Consumer Research, Vol. 16 No. 3, pp. 310-321

McGregor, S.L.T. (2012), “Complexity economics, wicked problems and consumer education”, International Journal of Consumer Studies, Vol. 36 No. 1, pp. 61-69.

McKelvey, S. (2004), “The growth in marketing alliances between US professional sport and legalised gambling entities: Are we putting sport consumers at risk?” Sport Management Review, Vol. 7 No. 2, pp. 193-210.

Milne, M. (2016), “Sports broadcasting rights”, in Milne, M.(ed.), The Transformation of Television Sport, Palgrave Macmillan, London, UK, pp. 75-103

Mitchell, R.K., Agle, B.R. and Wood, D.J. (1997), “Toward a theory of stakeholder identification and salience: defining the principle of who and what really counts”, Academy of Management Review, Vol. 22 No. 4, pp. 853-886.

Monaghan, S. and Derevensky, J. (2008), “An appraisal of the impact of the depiction of gambling in society on youth”, International Journal of Mental Health and Addiction, Vol. 6, pp. 537-550.

Mullin, B.J. (1985), “Characteristics of sport marketing,” in Lewis, G. and Appenzellar, H. (eds), Successful Sport Management, Michie Co., Charlottesville, VA, pp. 101-123.

Neghina, C., Caniels, M.C.J., Bloemer, J.M.M. and van Birgelen, M.J.H. (2015), "Value cocreation in service interactions: dimensions and antecedents”, Marketing Theory, Vol. 15 No. 2, pp. 221-242.

Newman, J. and Giardina, M. (2011), Sport, spectacle, and NASCAR nation: Consumption and the cultural politics, Palgrave Macmillan, London. 
Payne, A.F., Storbacka, K. and Frow, P. (2008), “Managing the cocreation of value”, Journal of the Academy of Management Science, Vol. 36, pp. 83-96.

Parry, K.D. (2009), “Search for the hero: An investigation into the sports heroes of British sports fans”, Sport in Society: Cultures, Commerce, Media, Politics, Vol. 12 No. 2, pp. 212-226.

Peetz, T.B., Parks, J.B. and Spencer, N.E. (2004), “Sport heroes as sport product endorsers: the role of gender in the transfer of meaning process for selected undergraduate students”, Sport Marketing Quarterly, Vol. 13 No. 3, pp. 141-151.

Peretti-Watel, P., Beck, F. and Legleye, S. (2002), “Beyond the u-curve: The relationship between sport and alcohol, cigarette and cannabis use in adolescents”, Addiction, Vol. 97 No. 6, pp. 707-716.

Polonsky, M.J. and Ryan, P. (1996), “The implications of stakeholder statutes for socially responsible managers”, Business and Professional Ethics Journal, Vol. 15 No. 4, pp. 3-36.

Post, J.E., Preston, L.E. and Sachs, S. (2002), “Managing the extended enterprise: The new stakeholder view”, California Management Review, Vol. 45 No. 1, pp. 6-28.

Rittel, H.W.J. and Webber, M.M. (1973), “Dilemmas in a general theory of planning”, Policy Sciences, Vol. 4 No. 2, pp. 155-169.

Rojek, C. (2006), “Sports celebrity and the civilizing process”, Sport in Society: Cultures, Commerce, Media, Politics, Vol. 9 No. 4, pp. 674-690.

Rowley, T.J. (1997), “Moving beyond dyadic ties: A network theory of stakeholder influences”, Academy of Management Review, Vol. 22 No. 4, pp. 887-910.

Rundle-Thiele, S., Russell-Bennett, R., Leo, C., and Dietrich, T., (2013), “Moderating teen drinking: combining social marketing and education”, Health Education, Vol. 113 No. 5, pp. 392-406. 
Saunders, S., Barrington, D. and Sridharan, S. (2015), "Redefining social marketing: Beyond behaviour change”, Journal of Social Marketing, Vol. 5 No. 2, pp. 160-168.

Shank, M.D. (2009), Sports Marketing: A Strategic Perspective, $4^{\text {th }}$ Ed, Pearson, Saddle River, N.J.

Shultz, C.J.II. and Holbrook, M.B. (2009), “The paradoxical relationships between marketing and vulnerability”, Journal of Public Policy \& Marketing, Vol. 28 No. 1, pp. 124-127.

Singer, B. and Kayson, S. (2004), “Partnerships, alliances, and stakeholder communication”, Social Marketing Quarterly, Vol. 10 No. 2, pp. 67-71.

Slater, M.D., Kelly, K.J., Edwards, R.W., Thurman, P.J., Plested, B.A., Keefe, T. and Wymer,W. (2011), “Developing more effective social marketing strategies”, Journal of Social Marketing, Vol. 1 No. 1, pp. 17-31.

Smith, A.C.T. and Stewart, B. (2012), "Body perceptions and health behaviors in an online bodybuilding community”, Qualitative Health Research, Vol. 22 No. 7, pp. 971-985.

Smith, A.C.T. and Stewart, B. (2007), “The traveling fan: Understanding the mechanisms of sport fan consumption in a sport tourism setting”, Journal of Sport \& Tourism, Vol. 12 No. 3-4, pp.155-181.

Smith, A.C.T. and Stewart, B. (2010), The special features of sport: A critical revisit”, Sport Management Review, Vol. 13 No. 1, pp. 1-13.

Stavros, C, Westberg, K, Wilson, B and Smith, A (2016), “Managing Behavior:

Organizational and consumer perspectives on athlete transgressions” in S. Chadwick, S., Chanavat, N and M. Desbordes M (Eds.) Routledge Handbook of Sports Marketing, Routledge, New York, USA, pp. 340-354. 
Stavros, C., Meng, M., Westberg, K. and Farrelly, F. (2014), “Understanding fan motivation for interacting on social media”, Sport Management Review, Vol. 17 No. 4, pp. 455469.

Stewart, B. (2007), “The political economy of football: Framing the analysis”, in Stewart, B. (ed.), The Games are Not the Same: The Political Economy of Football in Australia, Melbourne University Press, Carlton, pp. 23-42.

Stewart, B. and Smith, A. (2014), Rethinking Drug Use in Sport: Why the War on Drugs in Sport Will Never be Won, Routledge, U.K

Stewart, B. and Smith, A. (2000), “Australian sport in a postmodern age”, The International Journal of the History of Sport, Vol. 17 No. 2-3, pp. 278-304.

Temple, S., Long, T.,Wayman, J., Taubenheim, A., and Patterson, J. (2008), “Alliance building: mobilizing partners to share The Heart Truth with American women”, Social Marketing Quarterly, Vol. 14 No. 3, pp. 68-78.

Tomlinson, A. and Young, C. (2006), National Identity and Sports Events, SUNY Press, Albany.

van Bottenburg, M. (2003), “Thrown for a loss? (American) football and the European sport space”, The American Behavioral Scientist, Vol. 46 No. 11, pp. 1550-1562.

Vargo, S.L. and Lusch, R.F. (2016), “Institutions and axioms: an extension and update of service-dominant logic”, Journal of the Academy of Management Science, Vol. 44, pp. 5-12.

Vargo, S.L. and Lusch, R.F. (2008), “Service-dominant logic: continuing the evolution”, Journal of the Academy of Management Science, Vol. 36, pp. 1-10.

Veltri, E.R., Kuzma, A.T, Stotlar, D.K., Viswanathan, R. and Miller, J. (2003), “Athleteendorsers: Do they affect young consumer purchasing decisions?” International Journal of Sport Management, Vol. 4, pp. 145-160. 
Volkwein, K.A. (1995), “Ethics and top-level sport - a paradox?” International Review for the Sociology of Sport, Vol. 30 No. 3-4, pp. 311-321.

Waddington, I. (2000) Sport, Health and Drugs: A Critical Sociological Perspective, E \& FN Spon, London.

Waddington, I. and Smith, A. (2008), An Introduction to Drugs in Sport; Addicted to Winning, Routledge, Oxford, UK.

Wann (1995), "Preliminary validation of the sport fan motivation scale”, Journal of Sport and Social Issues, Vol. 19 No. 4, pp. 377-396.

Wann, D.L. and Branscombe, N.R. (1993), “Sports fans: Measuring degree of identification with their team”, International Journal of Sports Psychology, Vol. 24 No. 1, pp. 117.

Wann, D.L., Melnick, M., Russell, G. and Pease, D. (2001), Sport fans: The psychology and social impact of spectators, Routledge, New York, USA.

Wann, D.L. (2006), “The causes and consequences of sport team identification”, in Raney, A. and Bryant, J. (eds.), Handbook of Sports and Media, Lawrence Erlbaum, Mahwah, N.J., pp. 331-352.

Wenner, L. (1998), MediaSport, Routledge, New York.

Widdop, P., Cutts, D. and Jarvie, G. (2016), “Omnivorousness in sport: The importance of social capital and networks”, International Review for the Sociology of Sport, Vol. 51 No. 5, pp. 596-616.

Wiefferink, C., Detmar, S., Coumans, B., Vogels, T. and Paulussen, T. (2008), “Social psychological determinants of the use of performance-enhancing drugs by gym users”, Health Education Research, Vol. 23 No.1, pp.70-80.

Wilkinson, I. and L. Young (2002), “On cooperating: firms, relations and networks”, Journal of Business Research, Vol. 55 No. 2, pp. 123-132. 
Wilson, N. (1990), The Sports Business: The men and the money, Mandarin, London.

Woratschek, H., Horbel, C. and Popp, B. (2014), “The sport value framework: a new fundamental logic for analyses in sport management”, European Sport Management Quarterly, Vol. 14 No. 1, pp. 6-24.

Wright, G. (1999), “Sport \& globalisation”, New Political Economy, Vol. 4 No. 2, pp. 267281.

Zainuddin, N., Russell-Bennet, R. and Previte, J. (2013), “The value of health and wellbeing: an empirical model of value creation in social marketing”, European Journal of Marketing, Vol. 47 No. 9, 1504-1524.

Zaksaite, S. (2012), “The interrelation of micro and macro factors that contribute to cheating in sports”, Sport \& EU Review, Vol. 4 No. 2, pp. 9-23. 